\title{
Expression of resistin, CXCR3, IP-10, CCR5 and MIP-1 $\alpha$ in obese patients with different severity of asthma
}

\author{
Sara Rojas-Dotor ${ }^{1}$, Nora H. Segura-Méndez² ${ }^{2}$ Ken Miyagui-Namikawa² and Rafael Mondragón-González ${ }^{3}$ \\ ${ }^{1}$ Unidad de Investigación Médica en Inmunología. Hospital de Pediatría. Centro Medico Nacional SXXI, Instituto Mexicano del Seguro Social, México D.F. México. \\ 2 Departamento de Alergología e Inmunología Clínica. Centro Medico Nacional SXXI, IMSS, México D.F. México. \\ ${ }^{3}$ Unidad de Investigación Médica en Inmunoquímica. Centro Medico Nacional SXXI, IMSS, México D.F. México.
}

\begin{abstract}
Asthma studies suggest that alteration in the inflammation pattern may be associated with the severity of asthma. The aim of this study was to compare in vitro the expression of chemokines, chemokine receptors and cytokine production from CD4+ T human lymphocytes of asthmatic, both obese and non-obese patients with different severity levels of asthma. Lymphocytes were labeled with monoclonal anti-human CXCR3/IP-10, MIP-1 $\alpha$ /CCR5 antibodies and were analyzed by flow cytometry. Cell culture supernatants were used to measure production of interleukin IL-6 and resistin by ELISA. CXCR3/IP-10 expression increased in non-obese patients with mild persistent asthma $(2.2 \%, \mathrm{p}<0.05)$, moderate persistent asthma $(3 \%, \mathrm{p}<0.003)$ and severe persistent asthma $(4 \%, \mathrm{p}<0.004)$; this effect was stronger in obese patients with severe persistent asthma (35\%, $\mathrm{p}<0.004)$. MIP-1 $\alpha$ / CCR5 increased in non-obese patients with intermittent asthma $(0.65 \%, \mathrm{p}<0.05)$ and severe asthma $(1.4 \%, \mathrm{p}<0.03)$; in obese patients, this expression was greater in intermittent asthma $(8 \%, \mathrm{p}<0.05)$ and severe persistent asthma (12\%, $\mathrm{p}<0.04)$. Resistin production strongly increased in obese patients with intermittent $(976 \mathrm{ng} / \mathrm{ml})$ and severe persistent asthma (795 ng/ml). IL-6 increased in both lean and obese persons; however, the highest value was registered in the group of severe persistent obese asthmatics $(992 \mathrm{pg} / \mathrm{ml})$. Obesity per se increased the inflammatory profile of chemokines / cytokines secreted by cells of the blood, increasing the inflammatory status in asthmatic patients. Resistin showed characteristics of a pro-inflammatory cytokine mainly in severely obese asthmatics.
\end{abstract}

Key Words: Asthma classification, severity, chemokines (MIP-1 $\alpha$, IP-10), CC chemokine receptors (CXCR3, CCR5), interleukin-6, resistin.

\section{INTRODUCTION}

Allergic asthma is caused by a complex interaction among different types of immune cells in the airways. After exposure to the allergen, different cells such as alveolar macrophages, adipocytes, lymphocytes and eosinophils secrete different interleukins (IL)-6, -10, -4 and IL-13). These cytokines activate an inflammatory cascade and attract chemokines (IP-10, MIP1- $\alpha$ etc.) to activate chemokine receptors such as CXCR3 and CCR5, a crucial process of cellular infiltration in the lungs (Huber et al., 2008). Chemokines that cause inflammation include inhibitory protein 10 (IP)-10, also known as CXCL-10, macrophage inflammatory proteins $1 \alpha$ and $1 \beta$ (MIP-1 $\alpha-1 \beta$ or CCL3); these bind to CXCR3 and CCR5 respectively, and the chemokines that inhibit inflammation, such as monocyte chemoattractant protein 3 (MCP-3) or CCL7 and I-139 bind to CCR4 or CCR8 respectively (Barnes, 2000). Many of these mediators are synthesized and secreted by fat tissue cells, which cause an increase in the inflammatory response to the allergen in these patients (Fantuzzi, 2005). Resistin, a mediator also known as specific secretor factor in adipose tissue, is involved in insulin resistance induced by obesity and diabetes. Several studies have shown that resistin in humans, in contrast to its production by adipocytes in mice, is synthesized predominantly by mononuclear cells, both within and outside adipose tissue; it facilitates cellular infiltration and increases the width of fat tissues (Tilg and Moschen, 2006; Steppan, et al., 2001; Curat et al., 2006). Some studies in humans have failed to confirm the relationship between the circulating levels of resistin and the body mass index (BMI) and its role in insulin sensitivity (Bastard et al., 2002; Fasshauer and Paschke, 2003). However, some studies have reported increased resistin levels in overweight subjects and type 2 diabetes (McTernan et al., 2002; Vidal-Puig and Orahilly, 2001). Resistance to a cortisone-based treatment seems to be a failure in inhibiting cytokine production by lymphocytes, suggesting that different inflammatory cytokines which are associated with chemokines and chemokine receptors in the airways may be present in patients with different degrees of severity of asthma (Shannon et al., 2008). Asthma and obesity are public health concerns that have high impact and an increasing prevalence in recent years (Shore, 2007, 2008). Prospective studies have demonstrated that obesity is a risk factor for the development and exacerbation of asthma, and a positive correlation between body mass index and the development of asthma has been observed (Segura et al., 2007).

Other studies have shown that severe asthma has a higher prevalence in overweight patients compared to normal weight patients and that body mass index (BMI) is positively associated with clinical asthma severity. In addition, patients with more severe asthma have higher BMI than those with milder asthma (Saint-Pierre et al., 2006). Obesity has mechanical effects on lung function; it leads to a systemic proinflammatory status, thereby potentially increasing airway inflammation, and is associated with a number of co-morbid factors which might interfere with asthma control. Obesity does not cause airflow obstruction, but can result in pulmonary restriction and reduction in airway diameter, which could 
contribute to airway hyper-responsiveness. Mouse asthma models have demonstrated that obesity and cytokines can enhance airway hyper-responsiveness, airway inflammation and allergic responses, but it is unclear whether obesityassociated inflammatory mechanisms are relevant in human asthma (Beuther, 2009). The aim of this study was to compare, in vitro, the expression of chemokines, chemokine receptors and cytokine production by peripheral blood lymphocytes from healthy subjects and patients with different severity of asthma, with or without obesity.

\section{METHODS}

Subjects

All patients and volunteers gave their written informed consent for interviewing and blood sampling. The study was conducted according to the recommendations of the Declaration of Helsinki and approved by the local Ethics Committee. The sample consisted of fifty asthmatic patients, diagnosed with allergic asthma according to The Global Initiative for Asthma (GINA, 2008), which establishes a practical system of classification considering clinical and functional aspects such as frequency of diurnal and nocturnal respiratory symptoms and lung function; their combination allows us to classify asthma severity as: a) intermittent asthma, in which the main symptoms of breathlessness of varying intensity and duration, bronchial spasms, cough, mucus secretions, and wheezing occur less than once a week, maximum volume exhaled in the first second of a forced expiration $\left(\mathrm{FEV}_{1}\right)$ equal to or greater than $80 \%$ of predicted with less than $20 \%$ variability, b) mild persistent asthma, which consists of symptoms that occur at night, more than once a week, $\mathrm{FEV}_{1}$ greater than or equal to $80 \%$ of predicted with lower variability of $20-30 \%$, c) moderate persistent asthma, with exacerbated symptoms that affect activity and sleep and with the use of short-acting $\beta 2$ agonists on a daily application, $\mathrm{FEV}_{1}$ from 60 to $80 \%$ of predicted with greater than $30 \%$ variability, and d) severe persistent asthma, with daytime and nighttime symptoms that are frequently exacerbated and the use of short-acting $\beta 2$ agonists with daily application, $\mathrm{FEV}_{1}$ less than or equal to $60 \%$ of predicted with greater than $30 \%$ variability. We included clinical symptoms, spirometry and skin prick tests. In addition, we applied the following criteria: a) inclusion; age between 18 and 65 years for both sexes, obese and non obese (14 obese men and 12 women, 10 non-obese men and 14 women, 12 healthy subjects), residents of the metropolitan area of Mexico City, b) exclusion; patients with pulmonary diagnosis other than allergic asthma, history of immunotherapy in the past year, history of immunodeficiency or autoimmune diseases, smoking history and / or patients who have cooked with wood, confirmed pregnancy, who have used topical or systemic antihistamine-based therapies within two weeks prior to entering the study, who have received astemisol within the last two months prior to the execution of the skin prick test for mites, the presence of hives or dermographism, asthma attacks at any stage and residence less than a year in Mexico City. Patients were divided into three groups according to their body mass index (BMI) following the guidelines established by the World Health Organization (WHO) (Pauwels et al., 2001): obesity (BMI $\left.\geq 30 \mathrm{~kg} / \mathrm{m}^{2}\right)$, and non-obese $\left(\mathrm{BMI}<30 \mathrm{~kg} / \mathrm{m}^{2}\right)$ and healthy. After the taking the blood sample, the patients were treated with a combination therapy based on mometasone / formoterol (260 $\mu \mathrm{g})$ (Merck, California., USA) and oriented to control environmental factors (dust, pollen, cigarette smoke etc) that trigger asthma exacerbation. Healthy non-smoking subjects without obesity, hypertension, diabetes, or any other metabolic symptoms were used as controls.

Isolation of mononuclear cells from healthy subjects and patients with asthma

Fifteen $\mathrm{ml}$ of venous heparinized blood were obtained from asthmatic patients, both obese and non-obese, and healthy non-smoking adult volunteer donors $(n=62)$ of both sexes. The blood was diluted 1:3 with phosphate buffered saline (PBS; 0.15 $\mathrm{M}$ phosphate buffer). Blood was layered over $3 \mathrm{ml}$ of FicollHypaque (Sigma Chemical Co., St. Louis, Missouri, USA) with gradient $(\delta=1.077)$ and centrifuged at $1500 \mathrm{rpm}$ for $30 \mathrm{~min}$ at $21{ }^{\circ} \mathrm{C}$ (Böyum, 1968). The cellular interface peripheral blood mononuclear cells (PBMC) were collected and washed twice with PBS. Cell viability was determined using Trypan blue dye (Sigma Chemical Co., St Louis, MO); exclusion was $\geq 90 \%$.

\section{Cell culture}

Lymphocytes $\left(5 \times 10^{5}\right)$ were incubated for $24 \mathrm{~h}$ at $37{ }^{\circ} \mathrm{C}, 5 \%$ $\mathrm{CO}_{2}$ without stimulation in 24-well plates with RPMI-1640 medium supplemented with $10 \%$ fetal calf serum (FCS), $2 \mathrm{mM}$ L-glutamine, $100 \mathrm{U} / \mathrm{ml}$ streptomycin, $5 \mu \mathrm{g} / \mathrm{ml}$ gentamicin and $1 \mathrm{mM}$ sodium pyruvate (Gibco Laboratories, Grand Island, NY). Cells were harvested and centrifuged at $1500 \mathrm{rpm}$. The cell culture supernatants were collected and stored at $-70{ }^{\circ} \mathrm{C}$ until use.

\section{Cell Purification}

The cellular interface peripheral blood mononuclear cells (PBMC) were removed and washed two times with PBS. CD4+ $\mathrm{T}$ cells were purified using the CD4+ $\mathrm{T}$ cell isolation kit II, as an indirect magnetic labeling system for the isolation of untouched CD4+ T cells from human PBMCs (Miltenyi Biotec, Germany), and LS column and MidiMACS separator. Briefly, $1 \times 10^{7}$ PBMC cells were placed in propylene tubes with $80 \mu \mathrm{l}$ PBS-albumin-EDTA and $20 \mu \mathrm{l}$ cocktail of biotin-conjugated antibodies against CD8, CD11b, CD16, CD19, CD36, CD56, CD123, TCR $\gamma / \delta$ and CD235a (Glycophorin A) and were incubated for $10 \mathrm{~min}$ at $4{ }^{\circ} \mathrm{C}$. These cells were subsequently labeled magnetically with Anti-Biotin MicroBeads for depletion. The CD4+ lymphocytes obtained were 95\% pure. Acquisition of 10,000 events was conducted in flow cytometry FACSaria (BD Biosciences, Palo Alto, CA). For analysis Cell Quest software, version 3.1 (Becton Dickson, San Jose, CA) was used.

Immunofluorescent staining for chemokine and chemokine receptors

Lymphocytes were stained with monoclonal anti-human anti-MIP1 $\alpha$, anti- CCR5 or anti-IP-10, anti-CXCR3 antibodies coupled to fluorescein isothiocyanate (FITC) or phycoerythrin $(\mathrm{PE})$, respectively. Unconjugated isotype-matched control monoclonal antibodies were detected using anti-mouse IgG1FITC or -PE antibodies (PharMingen, San Diego, CA, USA). 
Briefly, $5 \times 10^{5} \mathrm{CD} 4+\mathrm{T}$ cells from each group were incubated in 24-well plates for $24 \mathrm{~h}$; after incubation, cells were centrifuged for $5 \mathrm{~min}$ at $400 \mathrm{~g}$ and supernatants were aspirated without disturbing the pellets. Cells were washed with PBS/0.5\% albumin/2mM EDTA. They were then marked with $\mathrm{mAb}$ and incubated for $20 \mathrm{~min}$ at $4{ }^{\circ} \mathrm{C}$ in the dark, and fixed with $1 \%$ p-formaldehyde (Sigma Chemical Co., St. Louis, MO) according to the manufacturer's instructions (PharMingen). Acquisition of 10,000 events was conducted in flow cytometry FACSaria (BD). For analysis, FACS Diva 6.1 software was used Miltenyi, et al., 1990.

\section{Quantification of resistin and IL-6}

Resistin and IL-6 in the cell culture supernatants were measured using commercially available enzyme-linked immunosorbent assay kits (ELISA) (Peprotech®, Rocky Hill, $\mathrm{NJ}$ ).

\section{Statistical analysis}

The statistical analysis was performed using the SPSS ${ }^{\circ}$ software, version 14.0 (SPSS Inc., Chicago. Illinois, USA) and MS Excel 2007. Quantitative data was expressed as mean and standard deviation (SD). Statistical comparison among groups was performed using the Mann-Whitney $U$ tests. Differences were considered as statistically significant when $p<0.05$. The relationship between in resistin production and the in IL-6 production were analyzed using normal distribution histograms with confidence intervals of $95 \%$.

\section{RESULTS}

\section{CXCR3 and IP-10 expression}

CXCR3 and IP-10 expressions were compared among obese and non-obese patients with with different degrees of severity of asthma (intermittent, mild persistent, moderate persistent, and severe persistent asthma), as well as with healthy subjects. In non-obese patients, CXCR3 and IP-10 expressions were not significantly different in intermittent asthmatic compared to controls (healthy subjects); this expression, however, increased gradually in patients with mild persistent asthma, moderate persistent asthma and severe persistent asthma, with statistically significant differences among groups $(2.2 \%$, $3 \%$ and $4 \%$ respectively; $\mathrm{p}<0.004$ ) (Fig. 1a). In obese patients with intermittent asthma, mild persistent asthma, moderate persistent asthma and severe persistent asthma CXCR3 and IP-10 were significantly over-expressed $(19 \%, 16 \%, 13 \%$ and $35 \%$ respectively; $\mathrm{p}<0.04)$ compared to healthy subjects and non-obese patients (Fig. 1b). Meanwhile, the expression was significantly lower in moderate persistent obese asthmatic $(13 \%, \mathrm{p}<0.05)$ and was the highest for obese patients with severe asthma $(35 \%, \mathrm{p}<0.001)$ (Fig.1b).

\section{MIP-1 $\alpha$ and CCR5 expression}

The expression of MIP-1 $\alpha$ and CCR5 in non-obese asthmatic patients was significantly increased in patients with intermittent asthma and severe persistent asthma $(0.6 \%$ and $1.4 \%, \mathrm{p}<0.05$ and $\mathrm{p}<0.03$ respectively) compared to healthy subjects. Expression levels in mild persistent asthmatic and moderate persistent asthmatic were lowest $(0.3 \%$ and $0.4 \%$, $\mathrm{p}<0.04$ and $\mathrm{p}<0.05$ respectively) as shown in Figure 2a. MIP- $1 \alpha$ and CCR5 expressions in obese, asthmatic patients increased significantly $(8 \%, 6 \%, 7 \%$ and $12 \%, \mathrm{p}<0.04$ respectively) in all groups compared to healthy subjects (Fig. 2b). There were considerable differences in the severe persistent asthmatic group $(12 \%, \mathrm{p}<0.04)$ compared to other groups (Fig. 2b). We also observed over-expression of MIP- $1 \alpha$ and CCR5 in obese patients compared to non-obese patients.

Production of cytokines $I L-6$ and resistin in obese and non-obese asthmatics patients compared to healthy subjects

The concentration of resistin strongly increased in obese patients with intermittent asthma and severe persistent asthma (976 ng/ml and $795 \mathrm{ng} / \mathrm{ml}$, respectively) (Fig. 3). Therefore, there was an increase in the production of resistin in obese patients compared to lean patients: Intermittent 976 vs. 190 $\mathrm{ng} / \mathrm{ml}$, moderate persistent 480 vs. $378 \mathrm{ng} / \mathrm{ml}$ and severe persistent 795 vs. $612 \mathrm{ng} / \mathrm{ml}$; except for the lean subjects with mild persistent asthma 715 vs. $417 \mathrm{ng} / \mathrm{ml}$ as shown in Figure 3. All obese patients, regardless of the degree of their disease, showed high levels of IL-6 compared to lean patients: intermittent asthma (742 vs. $600 \mathrm{pg} / \mathrm{ml})$, mild persistent asthma (776 vs. $552 \mathrm{pg} / \mathrm{ml})$, moderate persistent asthma (902 vs. $712 \mathrm{pg} / \mathrm{ml}$ ) and severe persistent asthma (992 vs. $839 \mathrm{pg} /$ ml) (Fig. 3).

\section{DISCUSSION}

The coordinated expression and binding of chemokines to their receptors seem to be differentially regulated in specific stages of asthma. In this study, CXCR3/ IP-10 and CCR5/ MIP-1 $\alpha$ were overexpressed in obese patients with severe persistent asthma, which is in agreement with the reported of Brasier (2008) in patients with severe persistent asthma who underwent bronchoalveolar lavage.

We also showed that obesity per se increased the inflammatory status of asthmatic patients, probably due to the chemotactic effect of chemokines secreted by the blood cells of asthmatics. Additionally, cell activation may modify the expression of chemokines and chemokine receptors, which, in alternate fashion, are essential for leukocyte recruitment during inflammation. Once activated, T lymphocytes acquire different migratory capacities and are, in fact, the key factor for an efficient immune-response regulation. Interestingly, we found an association between increased expression of CXCR3 / IP-10 and severity of disease in non-obese asthmatic patients, while in obese patients increased expression of these markers was only observed in intermittent obese asthmatics and obese individuals with severe persistent asthma. The classification of asthma severity was very useful to us to relate the different levels of asthma severity to the expression of inflammatory markers studied; however, asthma, as a chronic inflammatory disease shows variations in clinical manifestations and the degree of airflow obstruction, so its severity may change over time in the same patient, indicating that not all inflammatory markers correlate with levels severity of asthma, as reported in the intermittent asthma group, especially in obese patients.

The elevated expression of these molecules in humans in primary and more severe stages of the disease had not been previously reported. We show that higher BMI scores 


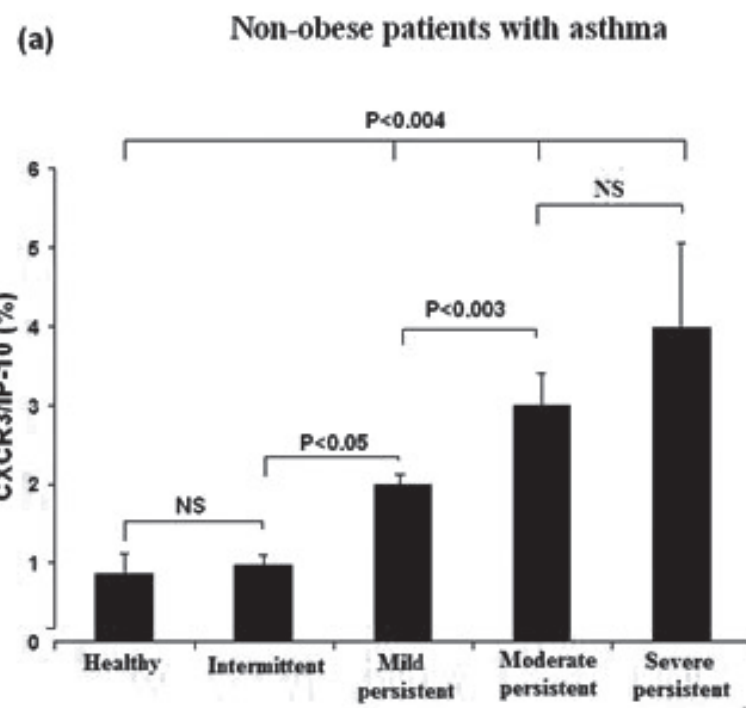

(b)

Obese patients with asthma

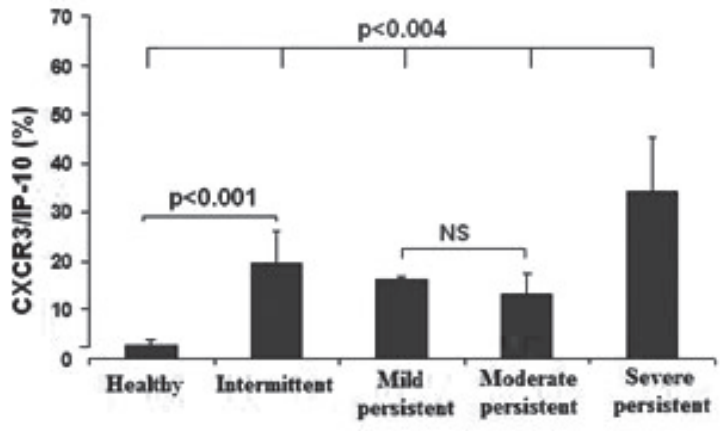

Fig.1
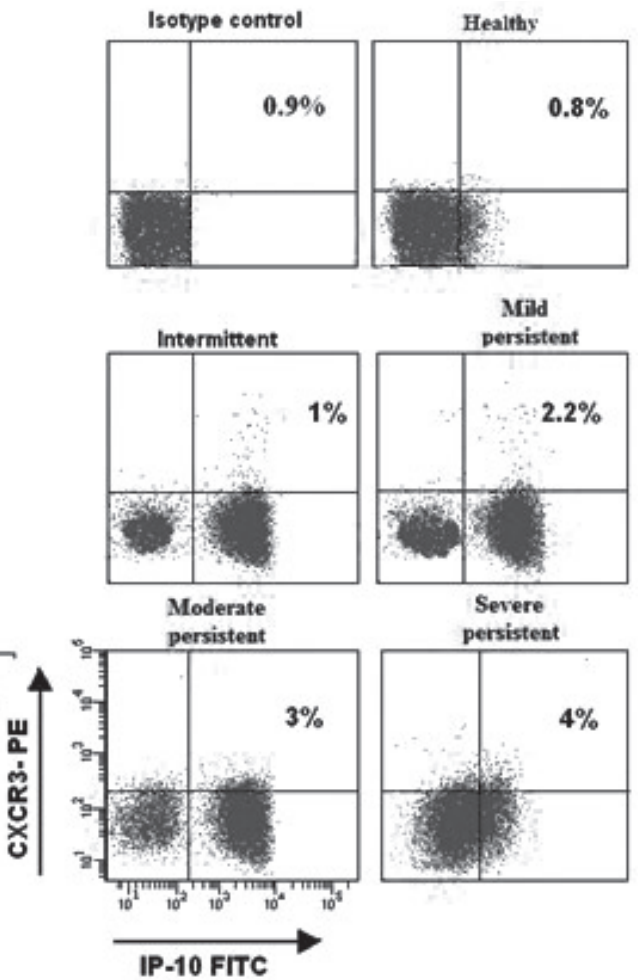

Isotype control
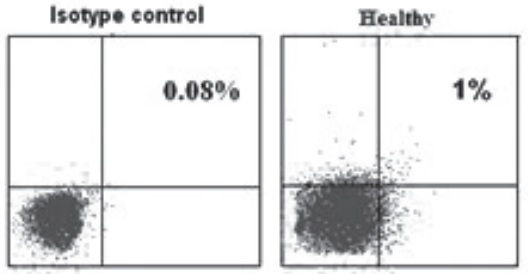

Intermittent
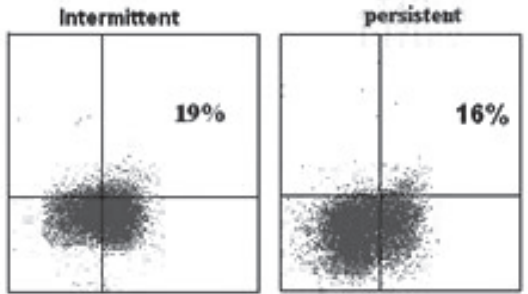

Moderate

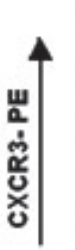

persistent
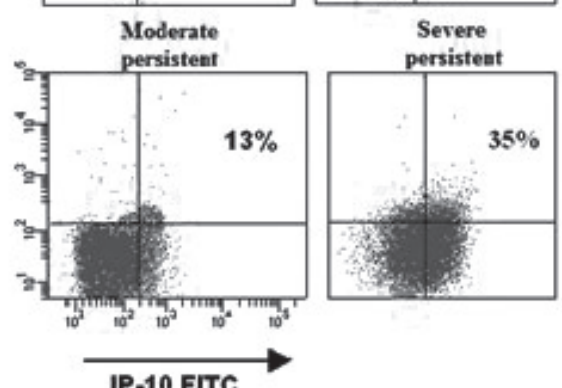

IP-10 FITC

Fig 1: Expression of IP-10 and CXCR3 in lymphocyte populations obtained from healthy subjects, non-obese patients with asthma and obese patients with asthma

Five $\times 10^{5}$ CD4+ lymphocytes were obtained from human peripheral blood (a) non-obese and (b) obese patients with intermittent, mild persistent, moderate persistent and severe persistent asthma and healthy subjects. The cells were isolated by the method of Böyum and purified to CD4 + T cells by the negative selection technique and were cultured for $24 \mathrm{~h}$. They were stained with fluorochromo-conjugated (FITC or PE) anti human IP-10 and CXCR3 monoclonal antibodies. 10,000 events were analyzed by flow cytometry. The quadrants were set with the isotype control (FITC or PE-conjugated mouse IgG). Bold histograms and numbers in the dot plots represent the mean \pm SD of positively stained cells from at least six independent experiments. The statistical differences between the groups were calculated using the Mann-Whitney $\mathrm{U}$ test. $\mathrm{p}<0.05$ was considered significant. 
(a)

Non-obese patients with asthma
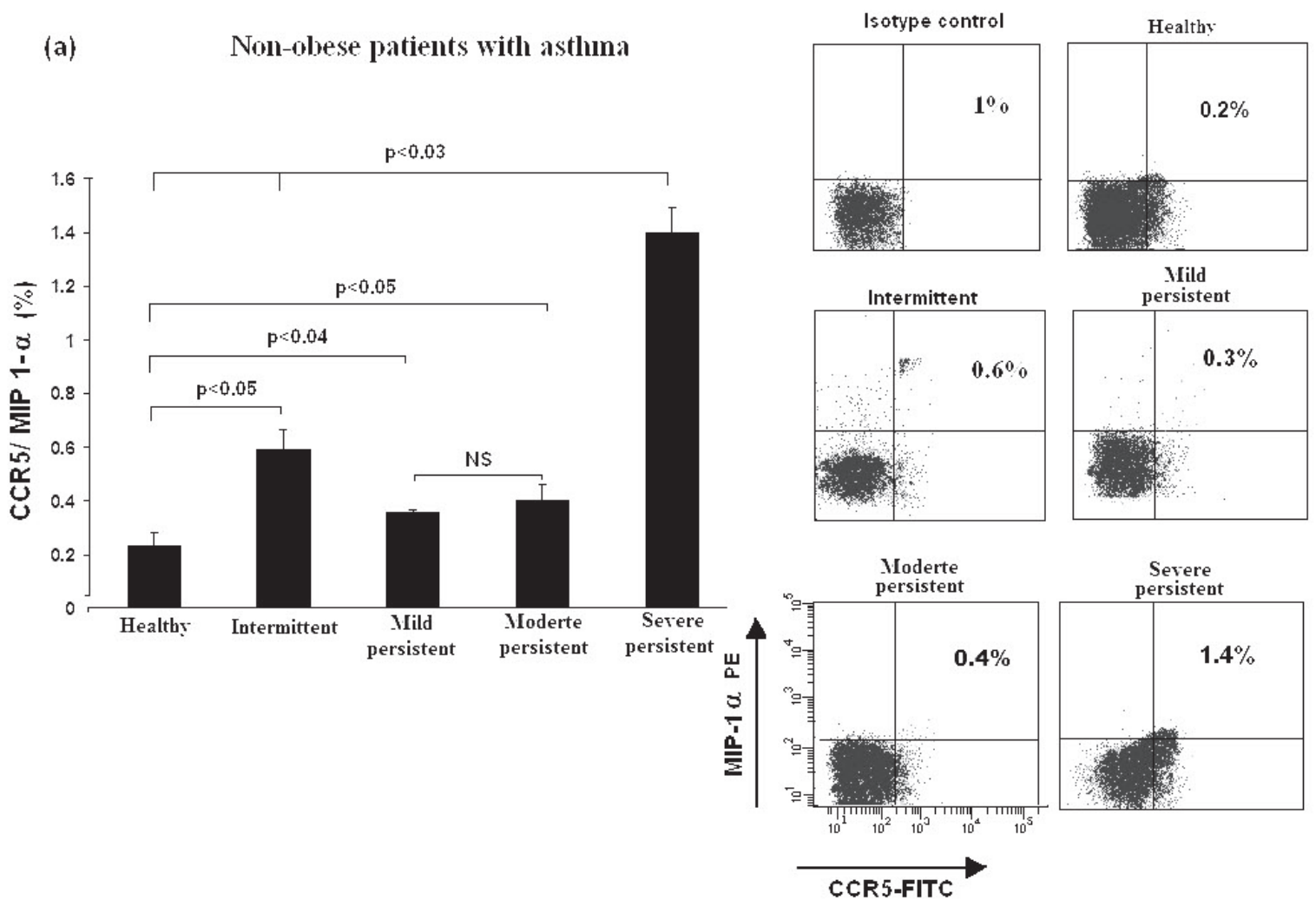

(b)

Obese patients with asthma

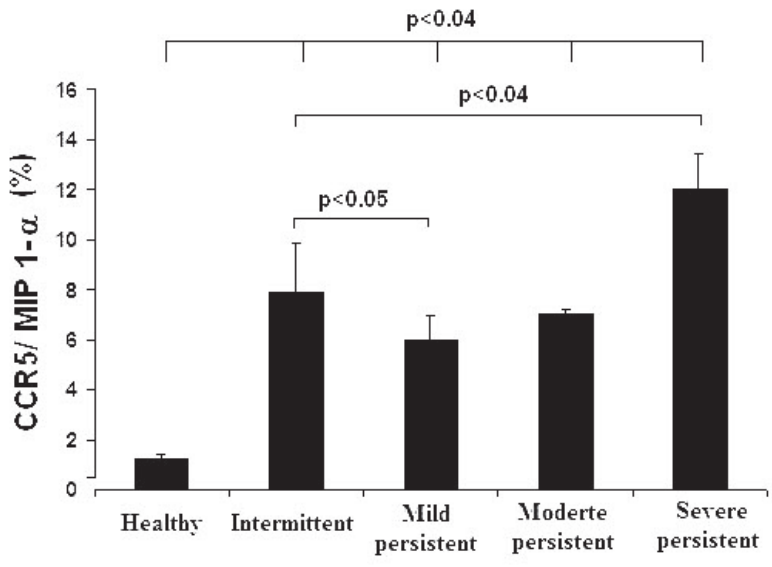

Fig. 2
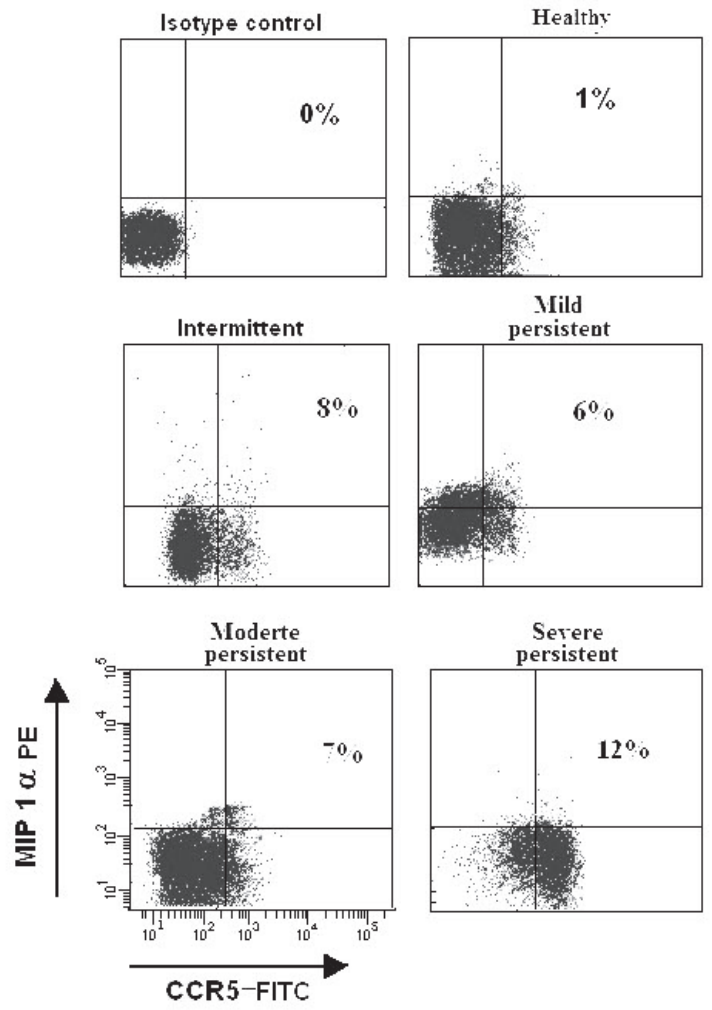

\section{Fig 2: MIP1 $\alpha$ and CCR5 expression in Iymphocytes from peripheral blood}

Five $\times 10^{5} \mathrm{CD} 4+$ lymphocytes were obtained from non-obese and obese patients with intermittent, mild persistent, moderate persistent and severe persistent asthma and healthy subjects and were cultured in 24 -well plates in a humidified chamber at $37{ }^{\circ} \mathrm{C}$ and $5 \% \mathrm{CO}_{2}$ for 24 h. Cells were stained with fluorochromo-conjugated (FITC or PE) anti human MIP 1- $\alpha$ and CCR5 monoclonal antibodies. At least 10,000 events were analyzed by flow cytometry. Black bars and bold numbers in the dot plots represent the mean \pm SD from five independent experiments. The quadrants were set with mouse IgG isotype control. The statistical differences between the groups were calculated using the Mann-Whitney $U$ test $(p<0.05)$. 
and elevated CXCR3/IP-10 expression levels (up to 9 times) are associated with increased asthma severity added to the condition of obesity. These findings highlight the importance of controlling theinflammation taking into account the role of obesity and it provides support for the assumptions that obesity-induced inflammation may contribute to greater asthma severity. The strong correlation between CXCR3 expression and Th1 differentiation led us to the hypothesis, subsequently verified in mouse models, that CXCR3 and its ligands regulate the migration of Th1 cells into sites of Th1driven inflammation (Lin et al., 2011); it also correlates with a study in which the expression of CXCR3 and its ligand IP-10 (CXCL10) was induced by IFN- $\gamma$ in mice challenged with an allergen in the lung (Gangur et al., 1998). High levels of IP10 and CXCR3 have been reported in co-cultured cells in the presence of INF- $\gamma$ in patients with chronic obstructive disease. IP-10 differs from other chemokines in its apparent specificity to activate $\mathrm{T}$ lymphocytes. We believe that it is also relevant in regulating the production and synthesis pattern of cytokines. These data imply that CCR5 and CXCR3 could be a potent therapeutic target of asthma for inhibiting the recruitment of T-cells to the airways.

Some limitations of the study deserve further discussion. To identify cells that express on their cell surface characteristic inflammatory markers we have often used invasive techniques such as bronchoalveolar lavage fluid, which was not performed in this study. Based upon the principle that cells migrate selectively to the inflammatory focus through chemokines and their receptors, a peripheral blood sample is less painful for the patient. In addition, the chemokine system in vivo is extremely redundant due to the large number of different chemokines, the overlap in chemokine function and the pleiotrophy of chemokine-receptor interaction. One of the challenges in this field is to identify which receptors play major roles in specific inflammatory conditions. The current findings suggest that the Th2-linked (CC) receptors are not the only potential targets for asthma therapy. The Th1-linked (CC) receptors, especially CCR5 and CXCR3, may also be valid targets. It was demonstrated that these markers play an important role in migratory behavior of peripheral blood $\mathrm{T}$ cells and influence the activation of $\mathrm{T}$ helper cells; however, we must be cautious in extrapolating these results to other population of lymphocytes such as CD8+ T cells and regulatory T cells.

The levels of many cytokines and other mediators may be elevated in obese patients and many be involved in systemic inflammation, such as interleukin $6, \mathrm{TNF}-\alpha$, and reactive $\mathrm{C}$ protein. Our data showed high concentrations of resistin and IL-6 in overweight asthmatic patients compared to healthy individuals, consistent with what has been reported in the literature (Bokarewa et al., 2005). In a previous study it was demonstrated that an increase in resistin is associated with the severity of asthma, which results in an increased expression of adhesion molecules such as VCAM- 1 and ICAM-1, as well as pro-inflammatory cytokines IL- 6 and TNF- $\alpha$, which trigger damage (Mondragón-González et al., 2007). IL-6 also activates $\beta 1$-integrin, which is a component of the VLA-4 complex and the ligand for fibronectin and VCAM-1, and thereby could influence cell attachment (Clahsen and Schaper, 2008). In this study, a strong increase in resistin and IL-6 levels was observed in obese patients with severe persistent asthma, while in thin patients with the same disease the production of these cytokines was significantly lower. Generally in overweight

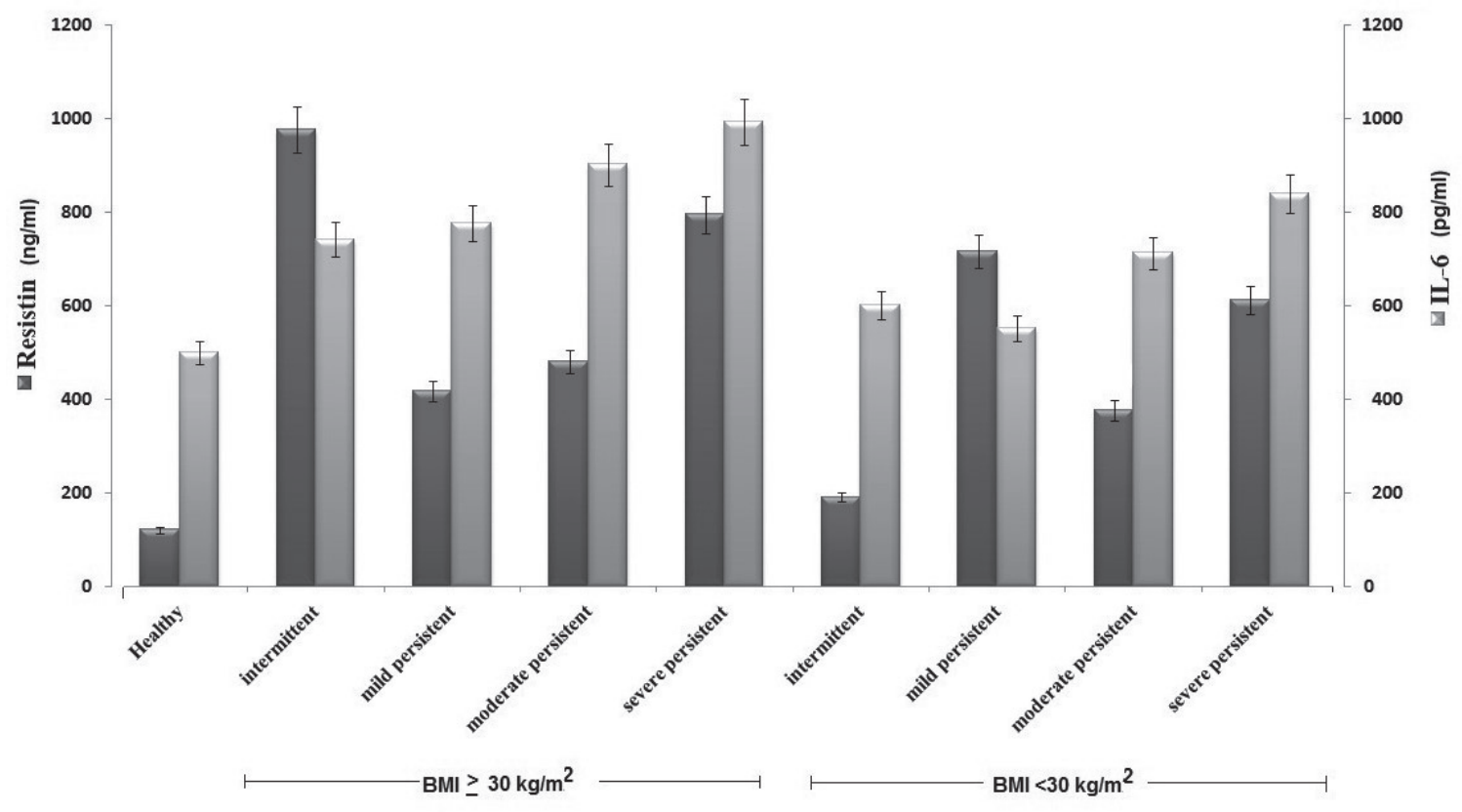

Fig 3: Resistin and IL-6 production by lymphocyte cells obtained from healthy subjects, lean patients and obese patients with different levels of severity of asthma

Cell culture supernatants were analyzed by ELISA to determine IL-6 and resistin production. The bars represent the average of three independent experiments in each group and the healthy subjects (control group). Quantitative data were expressed as normal distribution histograms with confidence intervals of $95 \%$. 
or obese individuals a considerable increase in adipocytes occurs, which increases IL-6 and resistin levels, and these in turn activate endothelial cells to stimulate migration of leukocytes and accumulation of leukocytes in the fatty adipose tissue. Under these conditions the increase in fatty tissue and expression of inflammatory cytokines contribute to the chronic inflammatory status, and they are characteristics of obesity. We observed this phenotype in intermittent asthma and severe asthma patients compared to the other asthma groups and healthy subjects. The production level of resistin in obese intermittent patients was elevated.This may be because resistin behaves as a prototype inflammatory cytokine, favoring the inflammatory process, and it also may have an additive effect with the inflammation that affects obesity. In lean patients the increased production of resistin was observed in patients with moderate persistent asthma and severe persistent asthma; of severity exacerbation of clinical symptoms was present at these levels. The relation between high concentrations of resistin and asthma severity obtained in our study agrees with the results obtained in in vivo studies (Mishra et al., 2007), in which it was found that resistin and IL-13 cause inflammation in airways and pulmonary remodeling in the lung of mice, resulting in the deposit of perivascular and peribronchial collagen fibers. Additionally, IL-6 and resistin could be induced by different allergens independent of Th2-cells, with biological and clinical adverse effects in patients with exacerbated asthma (Wolpe et al., 1998). In obese patients there is a condition of chronic systemic inflammation, which also means that if they have asthma, it is more severe than in lean persons and is difficult to control. In this study we found that the greater the overlap of groups, for example in severe persistent asthmatic obese it was poorer its final clinical status. In addition, obese asthmatics, regardless of the degree of severity of the disease showed high levels of IL-6, compared to healthy and non-obese patients. Hence there is a direct relationship between obesity, production of IL-6 and resistin, and cells migrating from the bloodstream the to inflammatory focus. We have previously reported that asthmatic patients with a BMI $\geq 30$ had a high concentration of leptin, especially women. In the current study, we showed that concentrations of IL- 6 and resistin, together with obesity, can be considered as indicators of asthma severity.

\section{CONCLUSION:}

Obesity per se increased the inflammatory profile of chemokines / cytokines secreted by cells of the blood by increasing the inflammatory status of asthma. Resistin shows characteristics of a pro-inflammatory cytokine, mainly in severely obese asthmatics. Chemokine receptors and their ligands, such as CXCR3/IP-10 and CCR5/MIP-1 $\alpha$, should be considered key inflammatory molecules in obese patients with different levels of asthma severity.

\section{ACKNOWLEDGMENTS}

This research was supported by the Consejo Nacional de Ciencia y Tecnología (CONACYT), México (No. 38104-M). The authors wish to thank American Journal Experts for the critical review of the English of the manuscript. The authors are grateful to laboratory technician José de la Luz Romero Preciado of the Blood Bank in Centro Médico Nacional SigloXXI-IMSS, México, D. F. México.

\section{REFERENCES}

BARNES, PJ (2000) Chronic obstructive pulmonary disease. N Engl J Mol 343: 269-280.

BASTARD JP, MAACHI M, VAN NHIEU JT, JARDEL C, BRUCKERT E, GRIMALDI A, ROBERT JJ, CAPEAU J, HAINQUE B (2002) Adipose tissue IL-6 content correlates with resistance to insulin activation of glucose uptake both in vivo and in vitro. J Clin Endocrinol Metab 7: 20842089.

BATEMAN ED, HURD SS, BARNES PJ, BOUSQUET J, DRAZEN JM, FITZGERALD $M$, GIBSON P, OHTA $K$, OBYRNE P, PEDERSEN SE, PIZZICHINI E, SULLIVAN SD, WENZEL SE, ZAR HJ (2008) Global strategy for asthma management and prevention: GINA executive summary. Eur Respir J 31: 143-178.

BEUTHER DA (2009) Obesity and asthma. Clin Chest Med 3: 479-88.

BOKAREWA M, NAGAEV I, DAHLBERGL, SMITH U, TARKOWSKI A (2005) Resistin, an adipokine with potent proinflammatory properties. J Immunol 174: 5789-5795.

BÖYUM A (1968) Isolation of mononuclear cells and granulocytes from human blood. Isolation of monuclear cells by one centrifugation and of granulocytes by combining centrifugation and sedimentation at $1 \mathrm{~g}$. Scand J Clin Lab Invest 97: 77-89.

BRASIER AR, VICTOR S, BOETTICHER G, JU H, LEE C, BLEECKER ER, CASTRO M, BUSSE WW, CALHOUN WJ (2008) Molecular phenotyping of severe asthma using pattern recognition of bronchoalveolar lavagederived cytokines. J Allergy Clin Immunol 121: 30-37.

CLAHSEN T, SCHAPER F (2008) Interleukin-6 acts in the fashion of classical chemokine on monocytic cells by inducing integrin activation, cell adhesion, actin polymerization, chemotaxis, and transmigration. J Leukoc Biol 84 : 1521-1529.

CURAT CA, WEGNER V, SENGENES C, MIRANVILLE A, TONUS C, BUSSE R. BOULOUMIE A (2006) Macrophages in human visceral adipose tissue: Increased accumulation in obesity and a source of resistin and visfatin. Diabetologia 49: 744-747.

FANTUZZI G (2005) Adipose tissue, adipokines and inflammation. J Allergy Clin Immunol 115: 911-919.

FASSHAUER M, PASCHKE R (2003) Regulation of adipocytokines and insulin resistance. Diabetologia 46: 1594-1603.

GANGUR V, SIMONS FE, HAYGLASS KT (1998) Links Human IP10 selectively promotes dominance of polyclonally activated and environmental antigen-driven IFN-gamma over IL-4 responses. FASEB J 12: 705-713.

HUBER J, KIEFER FW, ZEYDA M, LUDVIK B, SILBERHUMER GR, PRAGER G, ZLABINGER GJ,. STULNIG T M (2008) CC chemokine and CC chemokine receptor profiles in visceral and subcutaneous adipose tissue are altered in human obesity. J Clin Endocrinol Metab 93: 3215-3221.

LIN Y, YAN H, XIAO Y, PIAO H, XIANG R, JIANG L, CHEN H, HUANG K, GUO Z, ZHOU W, LU B, GAO J (2011) Attenuation of antigen-induced airway hyperresponsiveness and inflammation in CXCR3 knockout mice. Respir Res12:123.

MCTERNAN CL, MCTERNAN PG, HARTE AL, LEVICK PL, BARNETT AH, KUMAR S (2002) Resistin, central obesity and type 2 diabetes. Lancet 359: 46-47.

MISHRA A, WANG M, SCHLOTMAN J, NIKOLAIDIS NM, DEBROSSE CW, KAROW ML, ROTHENBERG ME (2007) Resistin-like molecule-beta is an allergen-induced cytokine with inflammatory and remodeling activity in the murine lung. Am J Physiol Lung Cell Mol Physiol 293: 303-304.

MONDRAGÓN-GONZÁLEZ R, SEGURA-MÉNDEZ NH, DEL RIVEROHERNÁNDEZ L, RODRÍGUEZ-VELASCO GJ, CRUZ-LÓPEZ M (2007) Association between adipocines and cellular adhesion molecules in asthmatic adults with or without obesity compared with healthy adults. Arch Alerg Inmunol Clin 38: 155-158.

PAUWELS RA, BUIST AS, MA P, JENKINS CR, HURD SS; GOLD Scientific Committee (2001) Global strategy for the diagnosis, management, and prevention of chronic obstructive pulmonary disease: National Heart, Lung, and Blood Institute and World Health Organization Global Initiative for Chronic Obstructive Lung Disease (GOLD): Executive summary. Respir Care 46: 798-825.

SAINT-PIERRE P, BOURDIN A, CHANEZ P, DAURES JP, GODARD P (2006) Are overweight asthmatics more difficult to control? Allergy 61: 79-84.

SEGURA MN, MURILLO GE, ROJAS-DOTOR S, RICO G, MARTÍNEZ HL, SANDOVAL SC (2007). Inflammatory markers associated with asthma and body mass index. Rev Alerg Mex 54: 96-200. 
SHANNON J, ERNST P, YAMAUCHI Y, OLIVENSTEIN R, LEMIERE C, FOLEY S, CICORA L, LUDWIG M, HAMID Q, MARTIN JG (2008) Differences in airway cytokine profile in severe asthma compared to moderate asthma. Chest 133: 420-426.

SHORE SA (2007) Obesity and asthma: Implications for treatment. Curr Opin Pulm Med 13: 56-62.

SHORE SA (2008) Obesity and asthma: Possible mechanisms. J Allergy Clin Immunol 121: 1087-1093.

STEPPAN CM, BAILEY ST, BHAT S, BROWN EJ, BANERJEE RR, WRIGHT CM, PATEL HR, AHIMA RS, LAZAR MA (2001) The hormone resistin links obesity to diabetes. Nature, 409: 307-312.
TILG H. MOSCHEN AR (2006) Adipocytokines: Mediators linking adipose tissue, inflammation and immunity. Natures Reviews Immunology 6: 772-783.

VIDAL-PUIG A, ORAHILLY (2001) Resistin: A new link between obesity and insulin resistance? Clin Endocrinol 55: 437-438.

WOLPE SD, DAVATELIS G, SHERRY B, BEUTLER B, HESSE DG, NGUYEN HT, MOLDAWER LL, NATHAN CF, LOWRY SF, CERAMI A (1998) Macrophages secrete a novel heparin-binding protein with inflammatory and neutrophil chemokinetic properties. J Exp Med 167: 570-581. 